\title{
Sexual health of teenagers in England and Wales: analysis of national data
}

\author{
Angus Nicoll, Mike Catchpole, Susan Cliffe, Gwenda Hughes, Ian Simms, Daniel Thomas
}

Sexual health is an essential component of general health and includes the avoidance of unintended pregnancies and sexually transmitted infections. Unintended pregnancies are associated with increased risk of poor social, economic, and health outcomes for mother and child, ${ }^{1}$ and important sequelae of sexually transmitted infections include pelvic inflammatory disease and infertility, cervical cancer, and increased susceptibility to HIV infection. For some of these factors teenagers are at greater risk than older women. ${ }^{12}$

\section{Subjects, methods, and results} sexual ill health among teenagers in England and Wales; birth and termination statistics from the Office for National Statistics; and reports from sexually transmitted disease clinics. ${ }^{3}$ We analysed data for 1996 and made comparisons with 1995.

In 1996 there were 86174 conceptions in females under age 20 years, of which 30296 were terminated and 55878 led to a maternity (still or live birth). Rates of termination of pregnancy among teenagers rose in 1996 compared with 1995 , by $14.5 \%$ in under $16 \mathrm{~s}$ and $12.5 \%$ in $16-19$ year olds. Maternity rates also rose in the two age groups by $6.7 \%$ and $4.6 \%$ respectively (table). The rises took place in all health regions and reversed previously declining trends in the early 1990s. When data were combined for 1995-6 and analysed by health district for females under age 16 (a Health of the
We reviewed all national routine data pertaining to
Nation indicator) we found substantial inequalities. Termination rates varied from 2.2 to 10.5 per 1000 and live births from 1.1 to 9.9 per 1000 , the highest rates being in urban districts. Teenage birth rates in England and Wales were the highest in western Europe (see $B M$ Js website for data).

In 1996, there were 2272 cases of gonorrhoea diagnosed and reported among teenagers aged 16-19 years attending sexually transmitted disease clinics in England and Wales. The numbers increased by $34 \%$ in women and 30\% in men from those of 1995 (table). The rises occurred in every region apart from Anglia and Oxford and followed a smaller rise between 1994 and 1995. Rates of gonorrhoea had consistently fallen from 1991 to 1994 . Widespread rises were also seen for genital chlamydial infection and warts but not for genital herpes simplex.

\section{Comment}

In 1996, teenage females accounted for $20 \%$ of all terminations but only $9 \%$ of births, and teenage females had the second highest termination rate after 20-24 year olds. Older female teenagers (age 16-19) had the highest rates of gonorrhoea, genital chlamydial infection, and warts and the second highest (after 20-24 year old women) rate of genital herpes simplex. ${ }^{3}$ Incidence of gonorrhoea has been identified as a sensitive indicator of trends in sexual behaviour. Older age groups were also affected by the rise in 1994-6, but the rises in
Editorial by McKee HIV and Sexually Transmitted Disease Division, Public

Health Laboratory

Service

Communicable

Disease

Surveillance Centre, London NW9 5EQ

Angus Nicoll, consultant

epidemiologist

Mike Catchpole, consultant

epidemiologist

Susan Cliffe,

senior scientist

Gwenda Hughes, principal scientist Ian Simms,

senior scientist

Public Health Laboratory Service

Communicable

Disease

Surveillance Centre Welsh Unit, Abton

House, Cardiff

CF4 3QX

Daniel Thomas, principal scientist

Correspondence to: Dr Nicoll anicoll@phls.co.uk

BMJ 1999;318:1321-2

Sexual health indices among teenagers in England and Wales, 1995-6

\begin{tabular}{|c|c|c|c|c|c|}
\hline & \multicolumn{2}{|c|}{1995} & \multicolumn{2}{|c|}{1996} & \multirow[b]{2}{*}{$\begin{array}{l}\% \text { rate increase } 1995-6 \\
(95 \% \mathrm{Cl})\end{array}$} \\
\hline & No & $\begin{array}{c}\text { Rate per } \\
1000\end{array}$ & No & $\begin{array}{c}\text { Rate per } \\
1000\end{array}$ & \\
\hline \multicolumn{6}{|l|}{ Terminations of pregnancy* } \\
\hline$<16$ year olds $\dagger$ & 3999 & 4.3 & 4550 & 4.8 & $14.5 \% \neq(9.7$ to 19.4$)$ \\
\hline 16-19 year olds $†$ & 30296 & 20.6 & 34752 & 23.2 & $12.5 \% \neq(10.8$ to 14.2$)$ \\
\hline \multicolumn{6}{|l|}{ Maternities* } \\
\hline$<16$ year olds $\dagger$ & 4035 & 4.3 & 4279 & 4.6 & $6.7 \% \ddagger(2.2$ to 11.4$)$ \\
\hline$<16-19$ year olds $\dagger$ & 55878 & 38.0 & 59612 & 39.8 & $4.6 \% \ddagger(3.4$ to 5.8$)$ \\
\hline \multicolumn{6}{|c|}{ New diagnoses at sexually transmitted disease clinics (16-19 year olds)§ } \\
\hline \multicolumn{6}{|c|}{ Women: } \\
\hline Gonorrhoea (uncomplicated) & 1024 & 0.79 & 1377 & 1.07 & $34.5 \ddagger(24.0$ to 45.8$)$ \\
\hline Chlamydia (uncomplicated) & 4940 & 3.82 & 5753 & 4.45 & $16.5 \ddagger(12.1$ to 21.0$)$ \\
\hline Genital herpes (first attack) & 1622 & 1.25 & 1646 & 1.39 & $1.5(-5.2$ to 8.7$)$ \\
\hline Genital warts (first attack) & 6737 & 5.21 & 7561 & 5.84 & $12.2 \ddagger(8.6$ to 16.0$)$ \\
\hline \multicolumn{6}{|l|}{ Men: } \\
\hline Gonorrhoea (uncomplicated) & 687 & 0.56 & 895ף & 0.71 & $31.3 \ddagger(19.2$ to 44.7$)$ \\
\hline Chlamydia (uncomplicated) & 1197 & 0.97 & 1411 & 1.15 & $17.9 \neq(9.1$ to 27.3$)$ \\
\hline Genital herpes (first attack) & 274 & 0.22 & 269 & 0.22 & $-2.5(-17.6$ to 15.3$)$ \\
\hline Genital warts (first attack) & 1821 & 1.49 & 2054 & 1.68 & $12.8 \ddagger(5.9$ to 20.1$)$ \\
\hline
\end{tabular}

${ }^{*}$ All conceptions of women resident in England and Wales leading to a termination of pregnancy in England and Wales and live or stillbirth (maternities) registered in England and Wales.

†Age at time of conception of pregnancy.

S Significant rate increase, $P<0.001$. Analyses for termination and birth data involved calculating confidence intervals for rate ratios which were subsequently

converted to percentage rate increase in 1996 compared with 1995. Analyses of data on sexually transmitted disease used Poisson linear regression with allowance for region effects.

§Agregate data on new diagnoses of sexually transmitted infections diagnosed and reported to the Department of Health and Public Health Laboratory Service by 30 September 1998

INumbers of cases of gonorrhoea diagnosed in 16-19 year old men that were attributed to homosexual transmission rose from 31 to 60 . website

extra

A further table of results is available website

www.bmj.com on the BMJ's 
numbers and rates among both sexes were greater among 16-19 year olds than any other age group. ${ }^{3}$ Overall attendances at sexually transmitted disease clinics have gradually risen since 1988, and increased use of services may have accounted for some of the 1994-6 rises, which continued into $1997 .{ }^{4}$ However, it seems unlikely that the pronounced rise could be attributed solely to a sudden widespread increase in clinic use.

There is substantial sexual ill health among teenagers in England and Wales. This is distributed inequitably, and recent data are consistent with a worsening trend. The potential for health gain through primary behavioural prevention is considerable, and the United States, which has even worse teenage rates than the United Kingdom, has recently shown such an improvement. ${ }^{5}$ Sexual health should be a priority for coordinated national and local health promotion among young people.

Contributors: AN collated the data, was the paper's main writer, and is the study guarantor. All the other authors were involved in the conceiving and drafting of the paper. $\mathrm{MC}$ was responsible for collection and analysis of data from sexually transmitted dis- ease clinics along with GH, IS, and DT (for data on cases reported by Welsh departments of genitourinary medicine). SC assembled data on births and terminations in England and Wales with assistance from Michael Bland. Statistical analyses by GH and SC were assisted by Pauline Rogers of the Public Health Laboratory Service Statistics Unit. Development of the manuscript was supported by Virginia Walker. Gathering of genitourinary clinic reports was delegated to the Communicable Disease Surveillance Centre by the Department of Health and the Welsh Office in 1996, which continue to support the work.

Funding: None

Competing interests: None declared.

1 Dickson R, Fullerton D, Eastwood A, Sheldon T, Sharp F. Preventing and reducing the adverse effects of unintended teenage pregnancies. Effective Health Care 1997:3:1-12.

2 Cowan FM, Mindel A. Sexually transmitted diseases in children: adolescents. Genitourin Med 1993;69:141-7.

3 Simms I, Hughes G, Swan AV, Rogers PA, Catchpole M. New cases seen at genitourinary medicine clinics: England 1996. CDR Supplement 1998;8 (suppl 1):S1-12.

4 Hughes G, Simms I, Rogers PA, Swan AV, Catchpole M. New cases seen at genitourinary medicine clinics: England 1997. London: Public Health Laboratory Service, 1998. http://www.open.gov.uk/cdsc/

5 Trends in sexual risk behaviour among high school students-United States 1991-1997. MMWR 1998;47:749-51.

(Accepted 30 October 1998)

\title{
Reporting of precision of estimates for diagnostic accuracy: a review
}

\author{
Robert Harper, Barnaby Reeves
}

Department of Ophthalmology, Manchester Royal Eye Hospital, Manchester M13 9WH Robert Harper, principal optometrist

Health Services Research Unit,

London School of Hygiene and Tropical Medicine London

WC1E 7HT

Barnaby Reeves, senior lecturer

Correspondence to: Dr Harper robert.harper@ man.ac.uk

BMJ 1999;318:1322-3
Diagnostic accuracy is usually characterised by the sensitivity and specificity of a test, and these indices are most commonly presented when evaluations of diagnostic tests are reported. It is important to emphasise that, as in other empirical studies, specific values of diagnostic accuracy are merely estimates. Therefore, when evaluations of diagnostic accuracy are reported the precision of the sensitivity and specificity estimates or likelihood ratios should be stated.$^{1-3}$ If sensitivity and specificity estimates are reported without a measure of precision, clinicians cannot know the range within which the true values of the indices are likely to lie.

Confidence intervals are widely used in medical literature, and journals usually require confidence intervals to be specified for other descriptive estimates and for epidemiological or experimental analytical comparisons. Journals seem less vigilant, however, for evaluations of diagnostic accuracy. For example, a recent review of compliance with methodological standards in diagnostic test research found that for the period 1978-93 only 12 of 112 studies published in the New England Journal of Medicine, JAMA, the BMJ, and the Lancet reported the precision of the estimates of diagnostic accuracy. ${ }^{3}$ We have found that the reporting of $95 \%$ confidence intervals for estimates is somewhat better in a more recent 2 year interval for studies published in the $B M J$ but still far from ideal.

\section{Methods and results}

We searched the Medline database (for 1996 and 1997) for reports of diagnostic evaluations in the BMJ. After we excluded letters, case reports, and review or education articles we identified 16 studies (references supplied on request). Only eight (95\% confidence interval $25 \%$ to $75 \%$ ) papers reported precision for the estimates of diagnostic accuracy, with two of these studies providing confidence intervals only for either predictive power values or likelihood ratios but not for the sensitivity or specificity estimates also reported.

\section{Comment}

Evaluations of diagnostic accuracy should be prescribed with confidence intervals. We have also recently reviewed the extent of compliance with the reporting of confidence intervals in the ophthalmic literature and concluded that evaluations of diagnostic tests in this specialty are similarly flawed. ${ }^{4}$ The omission of the precision of estimates for diagnostic accuracy can make a considerable difference to a clinician's interpretation of the findings of a study. For example, an evaluation of the sensitivity and specificity of an imaging system for the optic nerve head for the detection of glaucoma reported estimates of $89 \%$ and $78 \%$, respectively ${ }^{5}$; the $95 \%$ confidence intervals of these estimates (not reported in the paper) ranged from $80 \%$ to $98 \%$ for sensitivity and from $66 \%$ to $90 \%$ for specificity. For a test with poorer diagnostic accuracy, these 95\% confidence intervals would have been even larger for an equivalent sample size because of the dependence of the standard error of a proportion on the proportion itself (figure). The figure shows how the precision of the sensitivity or specificity estimate varies 